\title{
Original
}

\section{Biological and Chemical Assessment of DNA/Chitosan Complex Film}

\author{
Yusuke Inoue ${ }^{1)}$, Minoru Kawaguchi' ${ }^{2)}$, Ichiro Masui ${ }^{1)}$, Harumi Horibe' ${ }^{1)}$, Tetsuya Rikimaru ${ }^{1)}$, Madoka Kuroki ${ }^{1)}$, \\ Yuri Katsumata ${ }^{3)}$, Nana Mori ${ }^{4)}$, Tohru Hayakawa ${ }^{5)}$ and Tadao Fukushima(
}

\author{
1) Department of Dental Hygiene, Fukuoka College of Health Sciences, Fukuoka, Japan \\ 2) Department of Dental Engineering, Biomaterials Section, Fukuoka Dental College, Fukuoka, Japan \\ 3) Department of Oral and Maxillofacial Surgery, Oral Surgery Section, Fukuoka Dental College, Fukuoka, Japan \\ 4) Department of Odontology, Periodontology Section, Fukuoka Dental College, Fukuoka, Japan \\ 5) Department of Dental Engineering, Tsurumi University School of Dental Medicine, Yokohama, Japan \\ 6) Center for Regenerative Medicine, Fukuoka Dental College, Fukuoka, Japan \\ (Accepted for publication, July 14, 2014)
}

\begin{abstract}
Transparent DNA/chitosan complex film was prepared from DNA/chitosan complex powder via hydrothermal hot pressing. In this study, we investigated the binding of daunorubicin hydrochloride (DH), proteins adsorption (fibronectin and albumin), mineral deposition, and rat soft-tissue response to the DNA/ chitosan complex film to determine whether this film has potential for use in membranes for bone tissue engineering. The binding ratio of DH to DNA/chitosan complex film was very close to the excision number of 3.7 for the binding of DH by native DNA. This indicated that DNA in the complex did not denature as a result of hot pressing. Apatite was formed on the surface of the film after immersion in simulated body fluid. However, quartz crystal microbalance analysis showed that protein absorption to the DNA/chitosan complex was very low. It was found that this film has an affinity for minerals rather than proteins. Although the film remained in an almost unchanged configuration at 21 days after subcutaneous implantation, the response of rat soft tissues to the film was mild. These results suggest that DNA/chitosan complex film has potential for use as a membrane in bone tissue engineering.
\end{abstract}

Key words: DNA/chitosan complex, Hydrothermal hot-pressing, Protein binding, Biodegradation, Protective membrane

\section{Introduction}

Deoxyribonucleic acid (DNA) has suitable properties for use in biodegradable biomaterials such as a scaffolds and drug delivery systems. For example, DNA has phosphate groups, which have high affinity for calcium ions, and it is less antigenic than other macromolecules such as proteins and polysaccharides. However, it is difficult for native DNA alone to be used as a biomaterial because it is a water-soluble polymer. To address this limitation, Fukushima et al. ${ }^{1-3)}$ prepared cationic DNA/poly-L-amino acids [poly-L-arginine (poly-arg), poly-L-lysine (poly-lys) and poly-Lhistidine (poly-his)] and DNA/chitosan complexes, which were water insoluble, for the application of DNA as a new biodegradable medical material. It was reported that the complexes had no serious cytotoxicity and showed only a mild soft-tissue response in rats in the course of biodegradation.

Segura et al. ${ }^{4)}$ suggested that the clearance of scaffold materials

Correspondence to: Dr. Tadao Fukushima, Center for Regenerative Medicine, Fukuoka Dental College, 2-15-1, Tamura, Sawara-ku, Fukuoka, 814-0193 Japan; Tel: +81-92-801-0411; Fax: +81-92-801-4909; E-mail: tadaof@college.fdcnet.ac.jp in vivo has limited their application for tissue engineering even if they have advantageous biological properties as biomaterials. Thus, it is considered that the formability of biomaterials is very important for fitting into tissue defects during implantation.

Fukushima et al. ${ }^{5)}$ reported that DNA/chitosan complexes could be mold-fabricated by rinsing methods with PBS buffer, whereas DNA/poly-L-amino acids cationic complexes showed poor formability. However, Irie et al. ${ }^{6}$ reported that DNA-chitosan, DNA/poly-arg and DNA/poly-lys complex powders turned into transparent films by use of hydrothermal hot-pressing methods. They also suggested that these complexes could be useful for clinical treatments requiring thin membranes or films, such as protective membranes for stomatitis and incised oral wounds.

In bone tissue engineering, mixtures of inorganic biomaterials such as hydroxyapatite with blood or saline are filled into bone defects. However, these mixtures are excluded from bone defects if the barrier of the bone defect is not sufficient. The membranes used as a barrier and an overcoat are required to stay with the mixtures being used to repair the bone defects. The biodegradation 
rate of these membranes is very important for bone tissue engineering, because new bone formation may take more than 3 months after implantation. Thus, we considered that membranes with fast biodegradation rates are unsuitable as bone substitutes.

Irie et al. ${ }^{6}$ described in their study with DNA/chitosan and cationic poly-L-amino acids complex films that DNA/chitosan film was biodegraded within 90 days after implantation, whereas the other films biodegraded within 14 days. Thus, we considered that DNA/chitosan films could be a candidate membrane for use in bone tissue engineering, and we investigated whether this was the case.

The hydrothermal hot-pressing method heated the DNA/ chitosan complexes at $80^{\circ} \mathrm{C}$ with mechanical loading (30 MPa) during film processing ${ }^{6}$. It is not yet clear whether heating denatures DNA in the DNA/chitosan complex or not.

In this study, we firstly investigate the denaturation of DNA in DNA/chitosan films by a daunorubicin hydrochloride (DH) binding method, and secondly, investigated the apatite-forming behavior by immersing the film in simulated body fluid. We also examined the binding of various proteins to the film by quartz crystal microbalance (QCM) analysis. Finally, we explored the histological responses of rat soft tissues to the film.

\section{Materials and Methods \\ Preparation of DNA/chitosan complexes}

Salmon testes DNA (Maruha Nichiro Corporation, Tokyo, Japan), which has been cleaved with nuclease into 300-bp fragments, was used in this study. Chitosan $(500 \mathrm{mg}$; average molecular weight $=129,000$; Maruha Nichiro Corporation, Tokyo, Japan) was dissolved in $40 \mathrm{ml}$ of $0.2 \mathrm{~N} \mathrm{HCl}$. NaOH solution $(0.2$ $\mathrm{N}$ ) and distilled water were added gradually to the chitosan to bring the $\mathrm{pH}$ to 5.0 and the volume to $100 \mathrm{ml}$.

DNA (500 mg) was dissolved in $100 \mathrm{ml}$ of distilled water and then added to the chitosan solution. The mixture was stirred at 20 ${ }^{\circ} \mathrm{C}$ for $1 \mathrm{~h}$. The DNA/chitosan complex was collected by centrifugation at 9,000 rpm for $10 \mathrm{~min}$ and washed with distilled water, after which the DNA/chitosan complex was freeze-dried (FD-5, Eyela, Tokyo, Japan).

\section{Preparation of DNA/chitosan complex film}

Firstly, DNA/chitosan complex powder $(100 \mathrm{mg})$ and distilled water $(50 \mu \mathrm{l})$ were mixed, and DNA/chitosan complex powder disks with distilled water were prepared by the same method as described previously).

The fabricated disk (14 mm diameter and $1 \mathrm{~mm}$ height) was placed onto the surface of a PTFE sheet $(50 \mathrm{~mm} \times 50 \mathrm{~mm}, 0.3$ $\mathrm{mm}$ thickness) and then the another PTFE sheet was placed on the top surface of complex disk. The DNA/chitosan complex disk sandwiched by PTFE sheets was placed on the surface of a polyethylene terephthalate plate $(100 \mathrm{~mm} \times 100 \mathrm{~mm}, 1.0 \mathrm{~mm}$ thickness), which was placed onto the metal disk in the hydrothermal hot pressing machine (IMC-180C, Imoto Machinery Co., Ltd, Kyoto, Japan) and then another polyethylene terephthalate plate was placed on top of the PTFE sheet. The processing of the DNA/chitosan film was carried out by pressing the disk at $30 \mathrm{MPa}$ at $80{ }^{\circ} \mathrm{C}$ for $10 \mathrm{~min}$. After being cooled at room temperature, the film was trimmed and used for the following experiments.

\section{Intercalation and groove binding of daunorubicin hydrochloride within DNA/chitosan film}

DNA/chitosan film (20 mg) was immersed for $48 \mathrm{~h}$ at $20{ }^{\circ} \mathrm{C}$ in $5 \mathrm{ml}$ of $1.4 \times 10^{-3} \mathrm{~mol} / 1 \mathrm{DH}$ (Wako Chemicals, Osaka, Japan) aqueous solution. The absorbance from 400 to $600 \mathrm{~nm}$ of each solution was measured before and after the reaction with a V-560 spectrophotometer (Jasco Corp., Tokyo, Japan). The amounts of intercalated and bound DH in the films were calculated from the difference in the total peak area for absorbance from 400 to 580 $\mathrm{nm}$ before and after the reaction. All experiments were performed in triplicate.

\section{Apatite formation on the film}

The DNA/chitosan film $(10 \mathrm{~mm} \times 10 \mathrm{~mm}, 30 \mu \mathrm{m}$ thickness $)$ was immersed in $20 \mathrm{ml}$ of simulated body fluid (Hank's solution) ${ }^{7)}$ and stored at $37{ }^{\circ} \mathrm{C}$ for 3 and 21 days. The simulated body fluid was renewed weekly for the 21-day study period. The surface of each sample was observed using a field emission scanning electron microscope (FE-SEM; JSM-6330F, JEOL, Tokyo, Japan) after immersion. The crystallographic structure of the crystals formed on the DNA/chitosan film was analyzed by means of X-ray diffraction (XRD; Ultima 4, Rigaku, Tokyo, Japan) with an Xray source of $\mathrm{CuK} \alpha$ and a power of $44 \mathrm{kV} \times 50 \mathrm{~mA}$.

\section{Quartz crystal microbalance analysis of protein binding to the film}

A QCM with a resonant frequency of $27 \mathrm{MHz}$ (Affinix Q4, Initium Inc., Tokyo, Japan) and biotinylated DNA (20 bp, $1 \mu \mathrm{M}$ : Fasmac Co., Ltd., Atsugi, Japan) were used to measure the reaction amount of albumin $(100 \mu \mathrm{g} / \mathrm{ml}$; Sigma, St. Louis, USA) and fibronectin (100 $\mu \mathrm{g} / \mathrm{ml}$; Roche, Basel, Switzerland) to the DNA/ chitosan complex. Biotinylated DNA was immobilized on the $\mathrm{Au}$ electrode sensor surface of the QCM in accordance with methods described by Hayakawa et al. ${ }^{8}$.

The DNA-immobilized sensor was exposed to $500 \mu \mathrm{l}$ of TE buffer (containing $0.15 \mathrm{~mol} / \mathrm{l} \mathrm{NaCl}$ ). When the frequency of the sensor had stabilized, chitosan solution $(100 \mu \mathrm{g} / \mathrm{ml}$, Nacalai Tesque, Kyoto, Japan) was injected, and the frequency was monitored as a function of time. The binding amount of chitosan to DNA was determined from the frequency shift. Next, the sensor surface with DNA/chitosan complex was exposed to $500 \mu \mathrm{l}$ of 


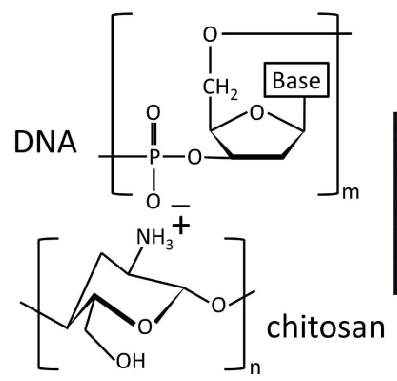

a

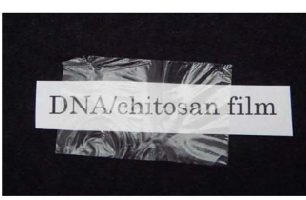

b

Figure 1. Schematic illustration of DNA/chitosan complex (a). Transparent complex film fabricated by hydrothermal hot pressing (b).

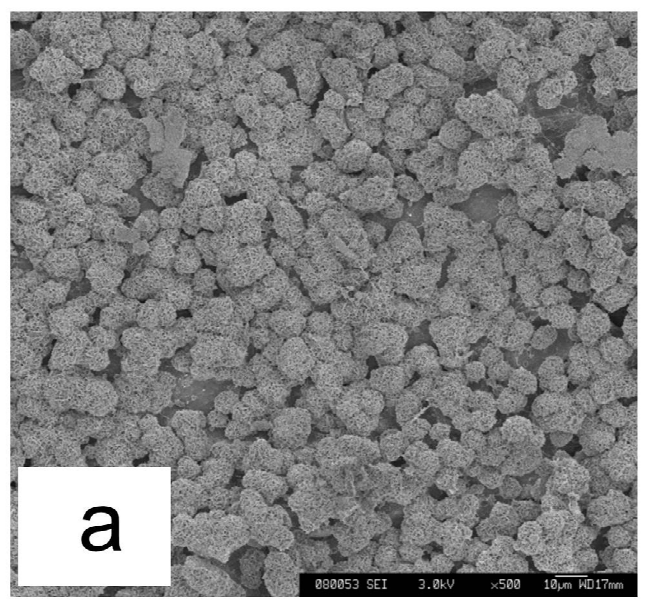

Figure 3. Field emission scanning electron micrographs of the DNA/chitosan complex film immersed in simulated body fluid for 3 days (a) and 21 days (b).

fresh TE buffer containing $0.15 \mathrm{~mol} / 1 \mathrm{NaCl}$. After stabilizing the frequency, aqueous solutions $(3 \mu \mathrm{l})$ of albumin or fibronectin were injected. The amounts of albumin and fibronectin binding to the DNA/chitosan complex were determined from the frequency shift. At $27 \mathrm{MHz}$, a frequency shift of $1 \mathrm{~Hz}$ corresponded to a mass change of an approximately $0.62 \mathrm{ng} / \mathrm{cm}^{2}$. All experiments were performed in triplicate.

\section{Implantation and histological evaluation}

Animal experiments (No. 07002) were performed in accordance with the ethical guidelines for animal experiments of Fukuoka Dental College. The studies were conducted using 6week-old male Sprague-Dawley rats weighing approximately 200 g. Surgery was performed under general anesthesia induced by 2 $\%$ isoflurane (Wako Chemicals, Osaka, Japan) and air mixture gas flowing at $1.0 \mathrm{l} / \mathrm{min}$ using an anesthesia gas machine (SFB01, MR Technology Inc., Tsukuba, Ibaraki, Japan). An incision was made in the back of the rats, and the complex film $(10 \mathrm{~mm} \times$ $10 \mathrm{~mm}$ ) was implanted subcutaneously. After the insertion of samples, the soft tissues were closed in separate layers by suturing with intracutaneously resorbable Vicryl 3-0 (Ethicon Inc.,
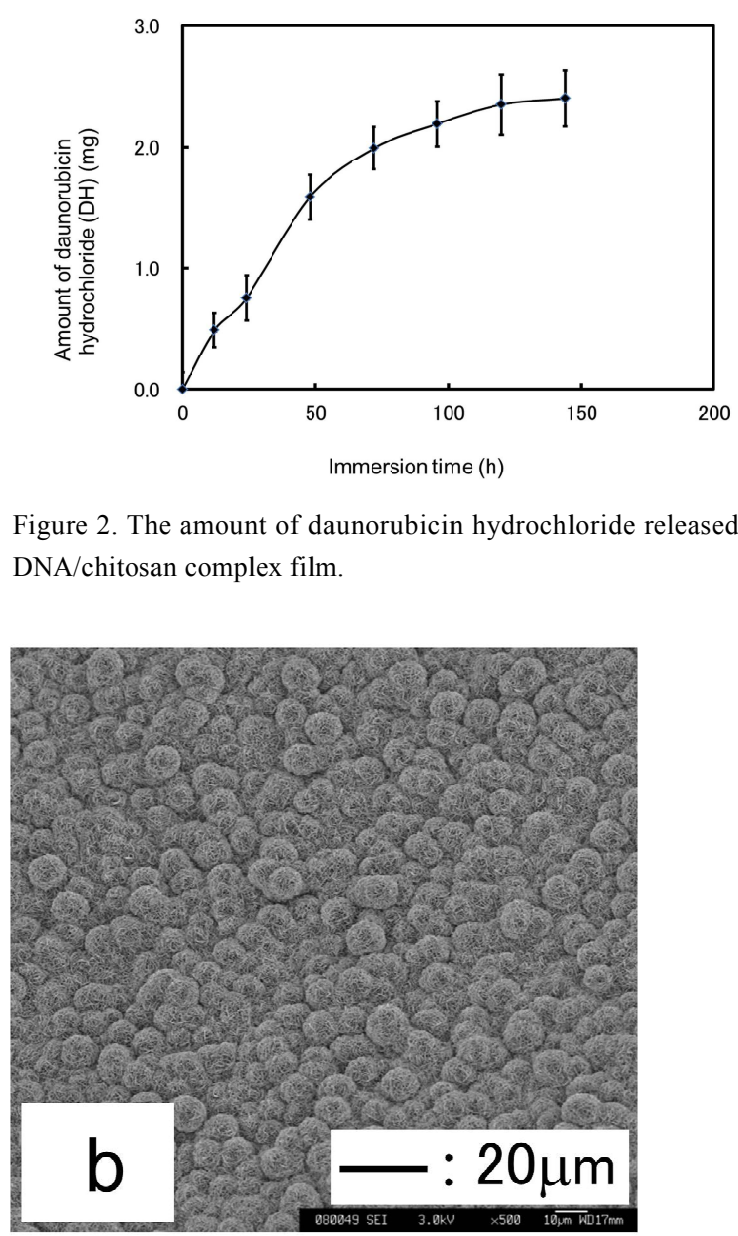

Figure 2. The amount of daunorubicin hydrochloride released from DNA/chitosan complex film.

Somerville, USA). The control was a group of sham-operated rats that did not undergo sample implantation. The rats (20 in total) were divided into two groups (one experimental group and one control group) for observation times of 14 and 21 days, respectively. Five rats were used for each group at each time point. At each time point, the animals were sacrificed by injection of an overdose of isoflurane. After sacrifice, the subcutaneous tissues containing the implanted film were excised immediately. They were fixed in $4 \%$ paraformaldehyde in phosphate buffer ( $\mathrm{pH} 7.4$ ), dehydrated with a graded alcohol series, cleared in xylene, and embedded in paraffin using routine procedures. The specimens were sectioned at $3 \mu \mathrm{m}$. The sections were stained with hematoxylin and eosin for histological observation using a light microscope (Eclipse 55i, Nikon, Tokyo, Japan).

\section{Results}

\section{Preparation of DNA/chitosan films}

A schematic illustration of the presumed structure of DNA/ chitosan complexes and the transparent complex film is shown in Fig. 1. The thickness of the DNA/chitosan complex film was approximately $30 \mu \mathrm{m}$. 


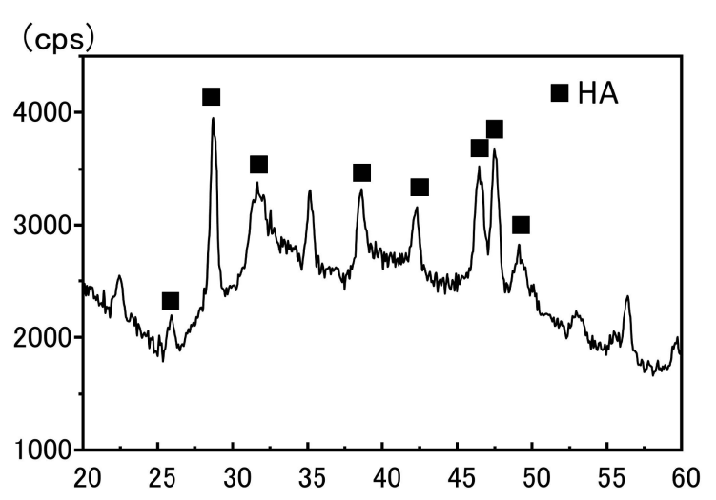

(20)

Figure 4. The XRD pattern of precipitates on the surface of the DNA/chitosan film after immersed in simulated body fluid (HA: hydroxyl apatite)

\section{Intercalation and groove binding of daunorubicin hydrochloride within DNA-chitosan films}

The cumulative amounts of intercalated and bound DH in the films are shown in Fig. 2. The amounts of intercalated and bound

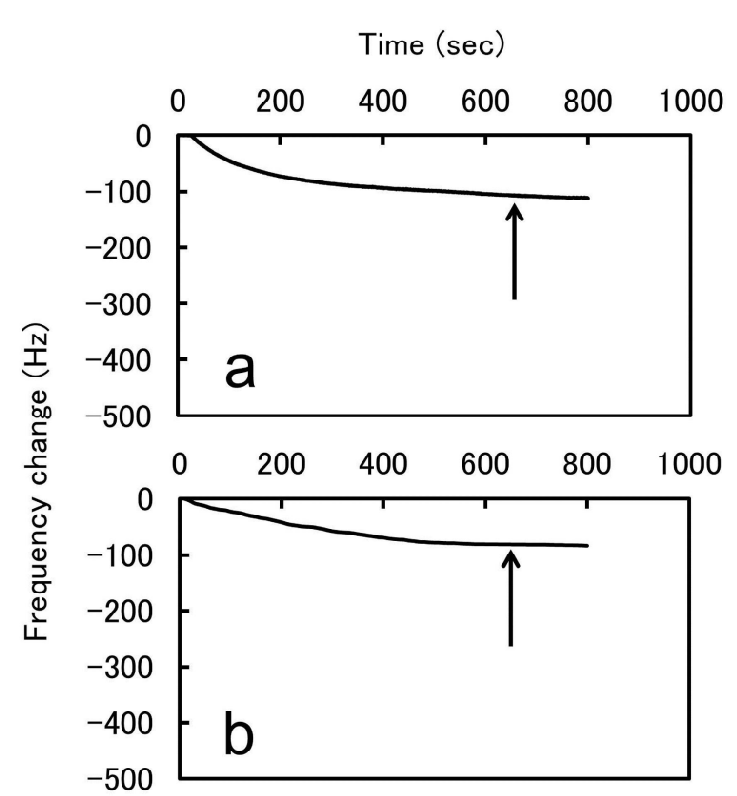

Figure 5. Frequency shift after albumin (a) and fibronectin (b) binding to biotinylated DNA/chitosan complex to a quartz crystal microbalance sensor. Arrows indicate a second injection of albumin or fibronectin.
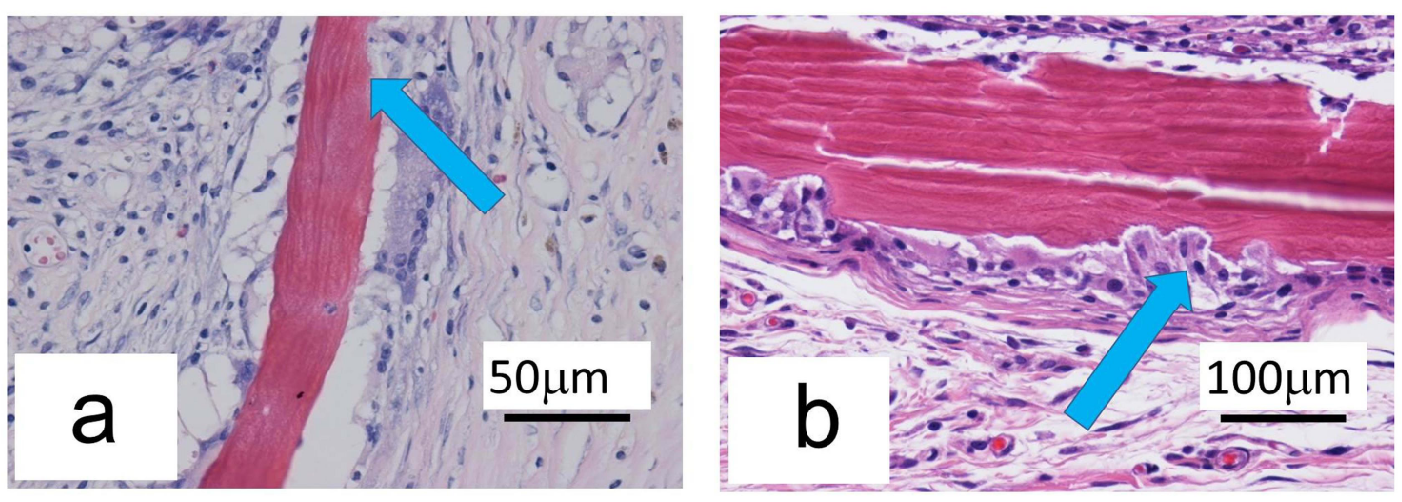

Figure 6. Histology of subcutaneous tissues of skin treated with the DNA/chitosan complex film after 14 days (a) and 21 days (b). Arrows indicate resorptive fossae of the film.

DH in the films increased with increasing immersion time within 24 hours after immersion and then plateaued. The colorless, transparent films changed to red, transparent films after immersion in DH solution. The amount of intercalated and groove-bound DH in the films was about $2.40 \mathrm{mg}$ after immersion for $144 \mathrm{~h}$. These results suggested that one molecule of DH intercalated and groove-bound to approximately $3.5 \mathrm{bp}$ of DNA.

\section{Apatite formation on the film}

Fig. 3 shows FE-SEM pictures of the DNA/chitosan film immersed in simulated body fluid for 3 and 21 days. Scanning electron microscopic observations revealed precipitate formation on the film. In the early stage (3 days' immersion), and globular precipitates were scattered over the surface of the film. At 21 days' immersion, the film was covered with larger amounts of globular precipitates. The amount of precipitate increased with immersion time.

Fig. 4 shows the XRD pattern of precipitates on the surface of the DNA/chitosan film after immersion. The XRD pattern shows diffraction lines characteristics of hydroxyapatite.

\section{QCM analysis of protein binding to the film}

The amount of DNA immobilized on the surface of $\mathrm{Au}$ in the QCM sensor averaged $349.0 \mathrm{ng} / \mathrm{cm}^{2}$, and the amount of chitosan electrically reacted to immobilized DNA on the sensors averaged $249.2 \mathrm{ng} / \mathrm{cm}^{2}$ (data not shown).

Fig. 5 shows the frequency shift of the QCM sensor after the binding of albumin or fibronectin to the biotinylated DNA/chitosan complex on QCM sensor. After injection of albumin or fibronectin, a decrease in frequency begun but later the changes in frequency 
were very small. Moreover, the frequency shift showed a plateau after the second injection (arrows) of albumin or fibronectin. The binding amounts of albumin or fibronectin to the biotinylated DNA/chitosan complex were $75.6 \mathrm{ng} / \mathrm{cm}^{2}$ and $52.7 \mathrm{ng} / \mathrm{cm}^{2}$, respectively.

\section{Implantation and histological evaluation}

Fig. 6 shows representative histological images of rat subcutaneous tissues after implantation of the DNA/chitosan film. The DNA/chitosan complex film remained almost fully intact at 14 days after implantation. Twenty-one days after implantation, a small amount of fragmented film was scattered in the implanted site. Multinuclear giant cells were noted in the adjacent portion of the implanted film on day 21 (Fig. 6b), and resided in the resorptive fossae of the film. These giant cells showed a phagocytic activity against the DNA/chitosan complex film. Fragmentation into small pieces and degradation of the complex film was not shown 21 days after implantation.

\section{Discussion}

In this study, we prepared a DNA/chitosan complex film from DNA/chitosan, powder via hydrothermal hot pressing in accordance with a previous study ${ }^{6}$. Similar transparent DNA/ chitosan complex film to that in previous study was obtained. Although this film was prepared at $80^{\circ} \mathrm{C}$, the effect of this temperature on denaturation of DNA in the complex is still unknown. Fukushima et al. ${ }^{2)}$ reported that DH intercalated with and bound to the groove of the DNA/chitosan complex, indicating that DNA in the complex maintained its double-stranded helical structure. Thus, we measured the amount of DH bound to the film in this study. A $144 \mathrm{~h}$-immersion resulted in the binding of one molecule of DH to approximately $3.5 \mathrm{bp}$ of DNA in the film. This is very close to the excision number of 3.7 for the binding of $\mathrm{DH}$ by native $\mathrm{DNA}^{9}$. This result indicated that heating to $80{ }^{\circ} \mathrm{C}$ did not denature DNA in the complex. It was also suggested that antibacterial activity could be generated by intercalating and groove binding of antibacterial materials such as acriflavine to the film.

Transparency is advantage for observation during convalescence because the wound is visible directly through the DNA/chitosan complex film. Moreover, it is considered that this film can be placed easily in narrow spaces such as spaces between alveolar bone and oral epithelium because this film is very thin.

Kawazoe et al. ${ }^{10)}$ reported that mesenchymal stem cells adhered and spread on the complex membranes at DNA/chitosan prepared at a DNA/chitosan ratio 1:1. However, the DNA/chitosan complex film showed poor dermal fibroblast cell attachment, with cells forming spheroids in spite of preparing the complex at a DNA/ chitosan ratio of $1: 1$ in the previous study ${ }^{6}$. It is well known that cells can attach to areas where proteins such as fibronectin, collagen, etc. had absorbed ${ }^{11-13)}$. Thus, we investigated the adsorption of fibronectin and albumin to films by QCM in this study. The level of adsorption of fibronectin and albumin to the films was very low (Fig. 5). Furuya et al. ${ }^{14)}$ reported that approximately $440 \mathrm{ng} / \mathrm{cm}^{2}$ of fibronectin absorbed on titanium (titanium sensor of QCM apparatus). The absorbed amount of fibronectin detected in the present study $\left(75.6 \mathrm{ng} / \mathrm{cm}^{2}\right)$ was approximately $17 \%$ of the absorbed amount reported by Furuya et al. Because many factors, including electrostatic interaction, hydrogen bonding and hydrophobic interaction ${ }^{15-18)}$, influence the adsorption of proteins onto biomaterials, the detailed mechanism of low protein adsorption is still unclear. We presumed that low protein adsorption affected poor dermal fibroblast cell attachment, resulting in cell spheroid formation. From these results, it may be expected that this film could be used as a membrane where adhesion needs to be prevented. Adhesion prevention is an advantage for a membrane because the film can be removed easily from the implantation area when retreatment is required, such as due to infection after implanting.

Unlike proteins, this film has good affinity for minerals such as a calcium compounds. As shown in Fig. 3, precipitated apatite formation on the surface of the film was observed within 3 days in simulated body fluid, and larger amounts of apatite were observed on the film after 21 days' immersion. These results corresponded with the results of immersion tests with the diskshaped DNA/chitosan complex in a previous study ${ }^{19}$. We considered that DNA/chitosan complex film will be useful as a membrane for bone tissue engineering.

Application of such films greatly depends on the biodegradation rate in vivo. Lu et al. ${ }^{20)}$ reported that degradation behavior is important for tissue-engineered cell/polymer construction involving cell growth and tissue regeneration. Nair and Laurencin ${ }^{21)}$ described that the degradation rate of materials should match the intended application and should not be higher than new matrix synthesis in vivo. In the case of this DNA/chitosan complex film used as a membrane for a bone tissues engineering, the film is required to keep almost to its original form for more than 3 months in vivo because new bone formation needs more than 3 months. In a previous study, it was found that most of films with $30 \mu \mathrm{m}$ thickness biodegraded within 90 days after implantation in soft tissues of rat. However, we considered that increasing the thickness of the film could slow the rate of biodegradation.

For biodegradable biomaterials, tissue response is very important during biodegradation. As shown as Fig. 5, the DNA/ chitosan complex film remained almost intact at 21 days after subcutaneous implantation and tissue responses were mild. Histological observations showed that macrophages and multinucleated giant cells actively phagocytosed the DNA/chitosan complex film at 21 days after subcutaneous implantation. It is 
well known that chitosan-decomposing enzyme are not present in humans ${ }^{22}$. Thus, we considered that the biodegradation of DNA/ chitosan complex film is mainly dependent on phagocytosis by macrophages and multinucleated giant cells.

In conclusion, transparent DNA/chitosan complex film of 30 $\mu \mathrm{m}$ thickness was prepared from DNA/chitosan complex powder via hydrothermal hot pressing. The binding ratio of DH to the DNA/chitosan complex film was very close to the excision number of 3.7 for the binding of DH by native DNA. This indicated that DNA in the complex did not denature during hot pressing. The DNA/chitosan complex film showed potential of apatite formation on the film after immersion in simulated body fluid within 3 days. From QCM analysis, low adsorption of fibronectin and albumin to the film was revealed. It was found that this film has an affinity for minerals rather than proteins. Although the complex film remained almost intact after 21 days' subcutaneous implantation, the response of rat soft tissues to the film was mild. Therefore, it is expected that $\mathrm{DNA} /$ chitosan complex film has potential for use as a membrane in bone tissue engineering.

\section{Acknowledgements}

This study was supported in part by a Grant-in-aid for Scientific Research (25670901) and by MEXT-Supported Program for the Strategic Research Foundation at Private Universities (S1001059), 2010-2015 from the Japan Society for the Promotion of Science. The authors are grateful to Maruha-Nichiro Corporation, Ltd. for supplying salmon testes DNA.

\section{References}

1. Fukushima T, Hayakawa T, Kawaguchi M, Ogura R, Inoue Y, Morishita K and Miyazaki K. PBS buffer solutions with different $\mathrm{pH}$ values can change porosity of DNA-chitosan complexes. Dent Mater J 24: 414-421, 2005

2. Fukushima T, Hayakawa T, Okamura K, Takeda S, Inoue Y, Miyazaki K and Okahata Y. Buffer solution can control the porosity of DNA-chitosan complexes. J Biomed Mater Res B Appl Biomater 76: 121-129, 2006

3. Fukushima T, Kawaguchi M, Hayakawa T, Ohno J, Iwahashi $\mathrm{T}$, Taniguchi K, Inoue Y and Takeda S. Complexation of DNA with cationic polyamino acid for biomaterial purposes. J Oral Tissue Engin 6: 24-32, 2008

4. Segura T, Anderson BC, Chung PH, Webber RE, Shull KR and Shea LD. Crosslinked hyaluronic acid hydrogels: a strategy to functionalize and pattern. Biomaterials 26: 359371,2005

5. Fukushima T, Ohno J, Hayakawa T, Kawaguchi M, Inoue Y, Takeda S, Toyoda M and Okahata Y. Mold fabrication and biological assessment of porous DNA-chitosan complexes. J Biomed Mater Res B Appl Biomater 91: 746-754, 2009

6. Irie A, Ohno J, Hayakawa T, Kido H and Fukushima T.
Transparent film formation of DNA/cationic polymer complexes by hydrothermal hot pressing: Observation of cell culture on films and biodegradation of films in vivo. J Hard Tissue Biol 22: 105-114, 2013

7. Hanawa T and Ohta M. Calcium phosphate naturally formed on titanium in electrolyte solution. Biomaterials 12: 767774, 1991

8. Hayakawa T, Fukushima T, Kawaguchi M, Inoue Y, Taniguchi $\mathrm{K}$ and Kaminishi H. Monitoring of DNA complex formation by means of quartz crystal microbalance. J Oral Tissue Engin 4: 61-67, 2006

9. Remeta DP, Mudd CP, Berger RL and Breslauer KJ. Thermodynamic characterization of daunomycin-DNA interactions: Comparison of complete binding profiles for a series of DNA host duplexes. Biochemistry 32: 5064-5073, 1993

10. Kawazoe N, Narita Y, Chen G, Satomi T and Tateishi T. Chitosan/dna polyelectrolyte complex membrane for controlling cell spreading and aggregation. Open Biotechnol J 2: 148-151, 2008

11. Curtis ASG and Forrester JV. The competitive effects of serum proteins on cell adhesion. J Cell Sci 71: 17-35, 1984

12. Vieggeert-Lankamp CL, Pego AP, Lakke EA, Deenen M, Marani E and Thomeer RT. Adhesion and proliferation of human Schwann cells on adhesive coatings. Biomaterials 25: 2741-2751, 2004

13. Zelzer M, Albutt D, Alexander MR and Russell NA. The role of albumin and fibronectin in the adhesion of fibroblasts to plasma polymer surfaces. Plasma Process Polym 9: 149156,2012

14. Furuya N, Wada T, Ozawa D, Yamanishi Y and Hayakawa T. Quartz-crystal microbalance monitoring for the adsorption of cell adhesive proteins onto a titanium surface. J Jpn Soc Oral Implant 25: 461-467, 2012

15. Kishida A, Iwata H, Tamada $\mathrm{Y}$ and Ikada Y. Cell behavior on polymer surfaces grafted with non-ionic and ionic monomers. Biomaterials 12: 786-792, 1991

16. Lakard S, Herlem G, Propper A, Kastner A, Michel G, VallesVillarreal N, Gharbi T and Fahys B. Adhesion and proliferation of cells on new polymers modified biomaterials. Bioelectrochemistry 62: 19-27, 2004

17. Arima $\mathrm{Y}$ and Iwata $\mathrm{H}$. Effect of functional groups on protein adsorption and subsequent cell adhesion using selfassembled monolayers. J Mater Chem 17: 4079-4087, 2007

18. Harnett EM, Alderman J and Wood T. The surface energy of various biomaterials coated with adhesion molecules used in cell culture. Colloids and Surface B: Biointerfaces 55: 90-97, 2007

19. Kawaguchi M, Ohno J, Iwahashi T, Fukushima T, Hayakawa $\mathrm{T}$ and Doi Y. Bone response of DNA-chitosan-apatite 
Yusuke Inoue et al.: Assessment of DNA/Chitosan Complex Film

complexes. J Oral Tissue Engin 7: 89-98, 2009

20. Lu L, Peter SJ, Lyman MD, Lai H-L, Leite SM, Tamada JA, Vacanti JP, Langer R and Mikos AG. In vitro degradation of porous poly(L-lactic acid) forms. Biomaterials 21: 15951605,2000
21. Nair LS and Laurencin CT. Polymers as biomaterials for tissue engineering and controlled drug delivery. Adv Biochem Eng Biotechnol 102: 47-90, 2005

22. Senel S and McClure SJ. Potential applications of chitosan in veterinary medicine. Adv Drug Deliv Rev 56: 1467-1480, 2004 
J.Hard Tissue Biology Vol. 23(4):399-406, 2014 